\title{
Potential Influences of the COVID-19 Pandemic on Drug Use and HIV Care Among People Living with HIV and Substance Use Disorders: Experience from a Pilot mHealth Intervention
}

\author{
Karli R. Hochstatter,2 ${ }^{1}$. Wajiha Z. Akhtar ${ }^{2} \cdot$ Sarah Dietz $^{2} \cdot$ Klaren Pe-Romashko $^{3}$. David H. Gustafson ${ }^{3}$. \\ Dhavan V. Shah ${ }^{3} \cdot$ Sarah Krechel $^{4} \cdot$ Cameron Liebert $^{4} \cdot$ Rebecca Miller $^{2} \cdot$ Nabila El-Bassel $^{1} \cdot$ Ryan P. Westergaard ${ }^{2,5}$
}

Published online: 23 July 2020

๑) Springer Science+Business Media, LLC, part of Springer Nature 2020

\begin{abstract}
People living with HIV (PLWH) and substance use disorder (SUD) are particularly vulnerable to harmful health consequences of the global COVID-19 pandemic. The health and social consequences of the pandemic may exacerbate substance misuse and poor management of HIV among this population. This study compares substance use and HIV care before and during the pandemic using data collected weekly through an opioid relapse prevention and HIV management mobile-health intervention. We found that during the pandemic, PLWH and SUD have increased illicit substance use and contact with other substance-using individuals and decreased their confidence to stay sober and attend recovery meetings. The proportion of people missing their HIV medications also increased, and confidence to attend HIV follow-up appointments decreased. Optimal support for PLWH and SUD is critical during pandemics like COVID-19, as drug-related and HIV antiretroviral therapy (ART) non-adherence risks such as overdose, unsafe sexual behaviors, and transmission of infectious diseases may unfold.
\end{abstract}

Keywords HIV $\cdot$ COVID-19 $\cdot$ Substance use disorder $\cdot$ Mobile-health intervention

\section{Resumen}

Personas con VIH y con trastornos por abuso de sustancias son más vulnerable a las consecuencias de la pandemia: COVID19. Dentro estas poblaciones, las consecuencias sociales y de la salud, causadas por la pandemia, pueden exacerbar el mal uso de las sustancias, y la adherencia a los antiretrovirales. Este estudio compara el abuso de sustancias y el cuidado del $\mathrm{VIH}$, antes y durante la pandemia, usando datos colectados semanal de otro programa que también investigo la prevención entre personas que han recaído con el uso de opioides y que tienen VIH. Nuestro análisis encuentra, que durante la pandemia, incrementaron el uso de sustancias ilícitas, y contacto con otras personas que usan sustancias, y perdieron la capacidad de mantenerse sobrios, y tambien dejaron de asistir reuniones de recuperación/apoyo. También, el porcentaje de personas con VIH no siguiendo con sus planes de tratamiento de VIH, incrementó; perdieron su motivacion en mantener sus citas médicos. Es muy crítico, durante una pandemia como COVID-19, tener recursos para personas que pertenecen a estas poblaciones, si no, casos de sobredosis, sexo sin protección y la transmisión de enfermedades infecciosas van a prevaler.

Karli R. Hochstatter

khochsta@medicine.wisc.edu

1 Social Intervention Group, Columbia University, 1255 Amsterdam Ave, New York, NY 10027, USA

2 Department of Medicine, School of Medicine and Public Health, University of Wisconsin, Madison, WI, USA
Center for Health Enhancement Systems Studies, Department of Industrial and Systems Engineering, University of Wisconsin, Madison, WI, USA

4 Vivent Health, Milwaukee, WI, USA

5 Bureau of Communicable Diseases, Wisconsin Department of Health Services, Madison, WI, USA 


\section{Introduction}

On March 11, 2020, the World Health Organization (WHO) declared COVID-19 a global pandemic [1]. COVID-19 is an illness caused by a novel betacoronavirus, SARS-CoV-2, which typically causes common cold symptoms and may cause severe pneumonia, respiratory failure, and even death [2]. Infection was first reported in late 2019 in Wuhan, China [3] and has since then spread rapidly across the globe from person to person through respiratory droplets [2].

Millions of Americans are experiencing the detrimental effects of this health, economic, and social crisis. Among the various marginalized communities who already suffer significant social and economic disadvantages and often live with poverty, health inequities, and other burdens are people living with HIV (PLWH) [4-6]. As the COVID-19 pandemic increases stress, anxiety, fear, sadness, and loneliness, PLWH, who are already disproportionately burdened by mental illness [7], are particularly vulnerable to worsening mental health. Conditions may be especially exacerbated among PLWH who have other medical comorbidities or poorly managed HIV (e.g. a low CD4 cell count or high viral load), and are more susceptible to severe illness from COVID-19 [8]. Poor mental health and social isolation are both strong risk factors for substance use disorders (SUDs), which also disproportionately affects PLWH [9, 10]. Increased substance use, which is highly correlated with risky sexual behavior and antiretroviral therapy (ART) non-adherence, has many dangerous consequences including overdose death and transmission of HIV and other blood borne diseases [11-15]. Therefore, it is important to monitor substance use behaviors among PLWH during the COVID19 pandemic to prevent drug-related risks.

Medical providers and public health services have taken drastic measures to prevent the spread of COVID-19, including canceling face-to-face visits and even closing clinics altogether. Mobile-health applications may provide a useful tool to collect data and retain PLWH and SUD in care during pandemics like COVID-19. Prior to the introduction of COVID-19, an existing mobile-health application, called A-CHESS, was implemented among PLWH and SUDs in Wisconsin to reduce substance use and improve HIV outcomes. The A-CHESS platform, described in detail elsewhere [16], was developed by the Center for Health Enhancement System Studies at the University of Wisconsin-Madison to support people with opioid use disorders. Key features of A-CHESS include public and private discussion forums, cognitive behavioral therapy boosters, games and relaxation activities to distract from cravings, hepatitis $\mathrm{C}$ virus and HIV educational information, and more [16, 17]. The goals of this ongoing pilot project are to tailor the
A-CHESS application to meet the complex needs of PLWH and SUD and test the effectiveness among this population. The aims of this paper are to determine whether (1a) substance use, including alcohol, marijuana, and other illicit substances, and (1b) precursors to substance use, including confidence to stay sober, recovery support meeting attendance, and being around other people using drugs, have increased and (2a) HIV ART adherence and (2b) confidence to attend their next HIV appointment have decreased during the COVID-19 pandemic among PWLH and SUD enrolled in this pilot project.

\section{Methods}

\section{Overview}

Research coordinators identified PLWH and SUD who were at high risk for treatment failure at HIV clinics in Wisconsin through provider referrals and by reviewing clinic's administrative databases. Enrollment began March 2019 and ended March 2020. Study participants have access to all A-CHESS support tools and are delivered brief surveys weekly to assess their general health status, mood, social support, drug use, and ART adherence for 12 months.

\section{Setting and Timeline}

Wisconsin is among the many regions heavily impacted by COVID-19, changing everyday lives as the sequence of events unfolded in early 2020. On February 5, the first case of COVID-19 was detected in Wisconsin. As the number of confirmed cases rose to seven on March 12, the governor of Wisconsin declared a State of Emergency. The next day, on March 13, he ordered all public and private K-12 schools to close by March 18. That same day, the President of the United States addressed the nation and declared the pandemic a national emergency. As confirmed cases in Wisconsin reached 72 on March 17, the governor announced a statewide ban on all gatherings with more than 10 people, and 1 week later, on March 24, a 'Safer at Home' order went into effect, ordering the closure of all non-essential businesses and urging citizens to stay at home to reduce the spread of COVID-19. As of May 4th, 2020, there were 8599 confirmed cases state-wide, but health officials warn that many more people are likely infected [18].

This study compares drug and alcohol use and HIV care reported on weekly surveys completed 6 weeks prior to a State of Emergency being declared in Wisconsin, from January 31 to March 12, to surveys completed 6 weeks after the 'Safer at Home' order went into effect, from March 24 to May 4. All weekly surveys completed during the period 
of rapidly spreading COVID-19 infections and changing government responses, from March 13 to March 23, were excluded because awareness and responsiveness to the pandemic varied substantially across the population.

\section{Measures}

Each week individuals were asked whether they used alcohol, marijuana, and other illicit drugs (including heroin, prescription opioids, cocaine, methamphetamine, or sedatives) in the past 7 days. They also were asked weekly whether they were around people using drugs when they were not expecting to be (yes or no), to rate their confidence to stay clean and sober on a scale from 1 (not confident at all) to 7 (very confident), and to rate their recovery support meeting attendance on a scale from 1 (no meetings) to 7 (many meetings).

Two HIV outcomes were assessed. First, individuals were asked on how many days in the past week they missed a dose of their HIV medications. Responses were dichotomized as $<2$ days or $\geq 2$ days, as missing 2 or more days in 1 week will likely cause viral rebound $[19,20]$. Second, they were asked to rate their confidence to keep their next appointment with their HIV care provider on a scale from 1 (not confident at all) to 7 (very confident).

\section{Statistical Methods}

Mixed effects logistic regression models, using clusterrobust standard errors to account for repeated surveys by individuals, were used to determine the odds of using alcohol, marijuana, and other illicit drugs before and during the pandemic, as well as the odds of being around people using drugs when they were not expecting to be and the odds of missing their HIV medication on $\geq 2$ days. Incidence rate ratios (IRRs) from mixed-effects Poisson regression, using cluster-robust standard errors, were used to compare individuals' confidence to stay clean and sober, recovery support meeting attendance, and confidence to keep their next HIV appointment. All regression models adjusted for gender, race, age, baseline employment status, whether they have ever been incarcerated, whether they have been diagnosed with a mental health disorder other than SUD, and whether they completed surveys during both study time periods or just one. A visual inspection of line graphs was used to understand trends before and during the pandemic. Chisquare and Fisher's exact tests were conducted to compare baseline characteristics between individuals included in the pre-pandemic sample and those in the later period. To test our directional hypotheses, we used a one-tailed test and $\alpha=0.05$ to determine statistical significance. All analyses were conducted in Stata/SE 16 [21].

\section{Results}

Between January 31 and March 12, 2020, 60 individuals completed 194 weekly surveys, and between March 24 and May 4, 2020, 43 individuals completed 148 weekly surveys. The number of surveys taken by each individual ranged from 1 to 6 in each time period, and 39 individuals completed surveys during both periods. Among the 64 unique individuals included in this analysis, $75 \%$ were male, $59 \%$ were Black or African American, 9\% were Hispanic or Latino, 66\% had ever been incarcerated, 39\% were employed at baseline, 39\% had a spouse or significant other, $70 \%$ were ever diagnosed with a mental health disorder other than SUD, $8 \%$ were on medication-assisted treatment for addiction, and the mean age was 49 (Table 1). There were no statistically significant differences between those included in each study period.

During the COVID-19 pandemic, there was no difference in the proportion of people using alcohol (41\%) or marijuana (32\%) compared to before the pandemic (Table 2). However, there was an increase in the proportion of people using other illicit substances (including heroin, prescription opioids, cocaine, methamphetamine, or sedatives), increasing from 10 to $18 \%$. After adjusting for demographics, study participants were 2.09 times more likely to use other illicit substances $(P=0.181)$. During the pandemic, the proportion of people reporting being around people using drugs

Table 1 Baseline demographics of analytical sample $(\mathrm{N}=64)$

\begin{tabular}{lc}
\hline & $\mathrm{N}(\%)$ \\
\hline Male & $48(75)$ \\
Race & \\
White & $22(34)$ \\
Black or African American & $38(59)$ \\
Mixed & $1(2)$ \\
Other & $3(5)$ \\
Hispanic or Latino & $6(9)$ \\
Ever incarcerated & $42(66)$ \\
Employed at baseline & $25(39)$ \\
Has a spouse/significant other & $25(39)$ \\
Receiving medication-assisted treatment ${ }^{\mathrm{a}}$ & $5(8)$ \\
Diagnosed with a mental health disorder other than SUD & $45(70)$ \\
Mental health disorders & \\
Anxiety/social anxiety & $19(30)$ \\
Bipolar/manic depression & $11(17)$ \\
Depression & $33(52)$ \\
Panic disorder & $1(2)$ \\
PTSD & $5(8)$ \\
Other & $7(11)$ \\
\hline
\end{tabular}

${ }^{a}$ One individual was on Methadone, three were on Vivitrol, and one was on Suboxone 
Table 2 Number (\%) of surveys reporting alcohol/drug use and HIV risks before and during the COVID-19 pandemic

\begin{tabular}{lllll}
\hline & $\begin{array}{l}\text { Before pandemic } \\
(\mathrm{N}=194)\end{array}$ & $\begin{array}{l}\text { During pandemic } \\
(\mathrm{N}=148)\end{array}$ & Odds ratio & Adjusted $P^{\mathrm{a}}$ value \\
\hline Alcohol & $79(41 \%)$ & $60(41 \%)$ & 0.974 & 0.480 \\
Marijuana & $62(32 \%)$ & $47(32 \%)$ & 0.474 & 0.291 \\
Other illicit drugs & $20(10 \%)$ & $27(18 \%)$ & 2.09 & 0.181 \\
Around people using drugs & $12(6 \%)$ & $18(12 \%)$ & 2.53 & $\mathbf{0 . 0 6 0}$ \\
Mean confidence rating for staying clean and sober & 5.35 & 4.77 & $0.886^{\mathrm{c}}$ & $\mathbf{0 . 0 0 7}$ \\
Recovery support meeting attendance rating & 3.02 & 2.24 & $0.727^{\mathrm{c}}$ & $\mathbf{0 . 0 0 1}$ \\
Missed ART dose on 2 or more days of the week & $10(5 \%)$ & $18(12 \%)$ & 2.81 & $\mathbf{0 . 0 4 2}$ \\
Mean confidence rating to keep next appointment with & 6.89 & 6.50 & $0.918^{\mathrm{c}}$ & $\mathbf{0 . 0 2 1}$ \\
$\quad$ HIV care provider & & & \\
\hline
\end{tabular}

Bold: statistically significant at $\alpha=0.05$ using a one-tailed test

${ }^{a}$ Adjusted for gender, race, age, baseline employment status, whether they have ever been incarcerated, and whether they have been diagnosed with a mental health disorder other than SUD

${ }^{\mathrm{b}}$ Other illicit drugs includes heroin, prescription opioids, cocaine, methamphetamine, and sedatives

${ }^{\mathrm{c}}$ Incidence Rate Ratio reported

when they were not expecting to be doubled from 6 to $12 \%$ $(P=0.060)$. Likewise, during the pandemic individuals had a rate 0.886 times smaller in their confidence to stay sober $(P=0.007)$, and a rate 0.727 times smaller in recovery support meeting attendance $(P=0.001)$.

During the pandemic, the proportion of participants missing their HIV medications 2 or more days per week significantly increased, from 5 to $12 \%$, compared to before the pandemic $(P=0.042)$. Similarly, there was a statistically significant decrease in individual's confidence to keep their next HIV appointment (IRR: 0.918, $P=0.021$ ).

Pre-pandemic, there was no increasing trend visible in the proportion of people using illicit substances, around other people using drugs, or missing HIV medications on 2 or more days (Fig. 1a). Likewise, there was no pre-pandemic decreasing trend visible in the mean confidence ratings for staying sober or keeping their next HIV appointment, nor for recovery support meeting attendance (Fig. 1b).

\section{Discussion}

By examining weekly survey data collected through an ongoing mobile-health intervention study, we found that PLWH and SUD in Wisconsin have increased their use of illicit substances during the COVID-19 pandemic. Individuals have also significantly decreased their confidence to stay sober and their recovery support meeting attendance, and they are unexpectedly around people using drugs more often. The significant worsening of these risk factors provides a strong concern that illicit substance use may further increase, and the use of alcohol and marijuana may begin to increase, throughout the course of the ongoing pandemic.
This study also found a significant increase in the proportion of people missing their ART medications 2 or more days per week. Poor ART adherence is the strongest predictor of failed virologic suppression, HIV drug resistance, disease progression, and even death among PLWH [22-24]. Missing 2 days of HIV medication, or adhering to only $71 \%$ of doses weekly, is well below the minimum level of adherence necessary to maintain viral suppression, which is often cited as between $80-95 \%$ [19, 20]. Furthermore, we found a significant decrease in individual's confidence to attend their next HIV appointment. Due to COVID-19, some providers have pushed back non-urgent medical appointments and/or provided virtual appointment options. We were unable to determine whether individual's confidence to attend a telehealth appointment may differ. However, previous research demonstrates that missing HIV appointments also predicts viral rebound, drug resistance, and mortality [25-27]. Together, these findings signal that novel methods to retain PLWH and SUD in HIV care during pandemics like COVID-19 must be implemented in order to improve the health of this marginalized population and prevent the spread of HIV.

The lack of any trends in these outcomes before the COVID-19 pandemic provides evidence that the worsening outcomes detected in this study are likely a result of the pandemic and not any pre-existing trends. However, our study had a small sample size, with the number of surveys taken per week ranging from 22 to 35 . Another limitation of this study is that we cannot assess the effect of the COVID-19 pandemic on drug use behaviors and HIV care among PLWH and SUD who do not have access to A-CHESS. Considering the goals of A-CHESS are to prevent substance misuse and lapses in HIV care, it is likely that this study underestimates the effect the pandemic has 

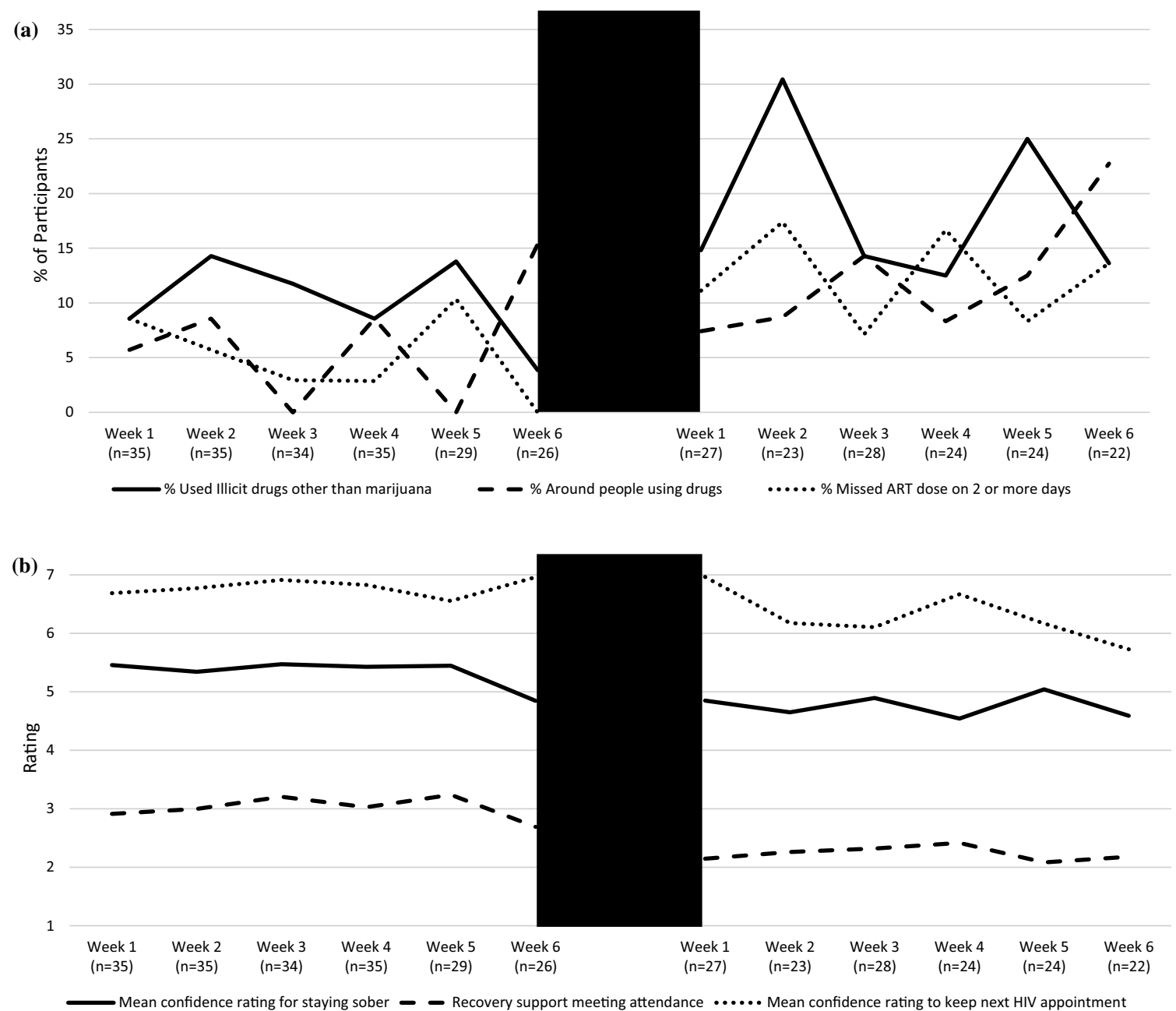

Fig. 1 Line graphs of trends in a the proportion of people using illicit drugs, around other people using drugs, and missing HIV ART medication on 2 or more days, and $\mathbf{b}$ mean rating for confidence to stay sober, recovery support meeting attendance, and confidence to attend

on substance use and HIV care. More research is needed to understand how the pandemic has impacted drug use and HIV care among PWLH and SUD, as well as the general population, who do not have access to support tools like A-CHESS.

Further research is needed to understand mediating factors in the relationship between this social, emotional, and economical public health crisis and substance use and HIV care. We found a decrease in recovery support meeting attendance during the COVID-19 pandemic. Although social-distancing orders prevented many recovery meetings from being held in person, most programs were offering virtual meetings. We were unable to assess whether meeting attendance decreased because individuals were not offered virtual meeting options, they refused virtual options due to personal preference and recovery needs, or they lacked next HIV appointment 6 weeks before the pandemic (January 31 to March 12, 2020) and 6 weeks during the pandemic (March 24 to May $4,2020)$

access to the necessary technology. Additionally, subjects reported unexpectedly being around people using drugs more often. We were unable to describe factors mediating this relationship using data. We do know, however, that selfquarantine and social-distancing measures have disrupted access to recovery meetings, employment, and other activities that take people outside their homes. Furthermore, people who use drugs are often housed with other drug-using individuals, either family/friends in their social networks or in sober living homes with others vulnerable to relapse. Therefore, contact with these individuals is likely increasing as the pandemic restricts people to their own living environments.

Optimal support for PLWH and SUD is critical during this pandemic, as drug-related and ART non-adherence risks such as overdose, unsafe sexual behaviors, and HIV 
transmission, may unfold. Exacerbating this crisis is that many harm reduction programs, such as syringe service programs, are operating at reduced hours or closed altogether. As face-to-face visits with medical and public health providers become less available, mobile-health interventions may provide a useful tool to remain connected, collect data, and deliver care to PLWH and SUD during pandemics like COVID-19. More research is needed to understand the longterm effects of COVID-19 on this population and to develop effective interventions that mitigate these effects and retain this population in care during pandemics.

Acknowledgements The authors want to particularly thank the individuals who participated in this study. This study was funded by the National Institutes of Health: NIDA (Grant DP2DA042424). Dr. Hochstatter is supported by the National Institutes of Health: NIDA (Grant T32DA037801).

\section{Compliance with Ethical Standards}

Conflict of interest The authors declare that they have no conflict of interest.

\section{References}

1. Cucinotta D, Vanelli M. WHO declares COVID-19 a pandemic. Acta Bio-Medica Atenei Parm. 2020;91(1):157-60.

2. Gandhi RT, Lynch JB, del Rio C. Mild or moderate covid-19. N Engl J Med. 2020. https://doi.org/10.1056/NEJMcp2009249.

3. WHO. Novel coronavirus - China. Geneva: World Health Organization; 2020. https://www.who.int/csr/don/12-january-2020-novel -coronavirus-china/en/. Accessed 26 Apr 2020.

4. Economically DisadvantagedIHIV by Group/HIV/AIDSICDC. 2019. https://www.cdc.gov/hiv/group/poverty.html. Accessed 26 Apr 2020.

5. Pellowski JA, Kalichman SC, Matthews KA, Adler N. A pandemic of the poor: social disadvantage and the U.S. HIV epidemic. Am Psychol. 2013;68(4):197-209.

6. American Psychological Association. Health disparities in HIV/AIDS, viral hepatitis, sexually transmitted diseases, and tuberculosis in the United States: Issues, burden, and response: (407322008-001). Worcester: American Psychological Association; 2007. https://doi.apa.org/get-pe-doi.cfm?doi=10.1037/ e407322008-001. Accessed 26 Apr 2020.

7. NIMH » HIV/AIDS and Mental Health. https://www.nimh.nih. gov/health/topics/hiv-aids/index.shtml. Accessed 26 Apr 2020.

8. CDC. Coronavirus Disease 2019 (COVID-19). Centers for disease control and prevention; 2020. https://www.cdc.gov/coron avirus/2019-ncov/need-extra-precautions/hiv.html. Accessed 26 Apr 2020.

9. NIMH » Substance Use and Mental Health. https://www.nimh. nih.gov/health/topics/substance-use-and-mental-health/index .shtml. Accessed 26 Apr 2020.

10. Hosseinbor M, Yassini Ardekani SM, Bakhshani S, Bakhshani $\mathrm{S}$. Emotional and social loneliness in individuals with and without substance dependence disorder. Int J High Risk Behav Addict. 2014;3(3):e22668.
11. Cohn SE, Jiang H, McCutchan JA, Koletar SL, Murphy RL, Robertson KR, et al. Association of ongoing drug and alcohol use with non-adherence to antiretroviral therapy and higher risk of AIDS and death: results from ACTG 362. AIDS Care. 2011;23(6):775-85.

12. Leigh BC. Alcohol and unsafe sex: an overview of research and theory. Prog Clin Biol Res. 1990;325:35-46.

13. Stall R. The prevention of HIV infection associated with drug and alcohol use during sexual activity. Adv Alcohol Subst Abuse. 1987;7(2):73-88.

14. Berg CJ, Michelson SE, Safren SA. Behavioral aspects of HIV care: adherence, depression, substance use, and HIV-transmission behaviors. Infect Dis Clin N Am. 2007;21(1):181-200.

15. Haverkos HW. Infectious diseases and drug abuse. Prevention and treatment in the drug abuse treatment system. J Subst Abuse Treat. 1991;8(4):269-75.

16. Gustafson D, Landucci G, Mctavish F, Kornfield R, Johnson $\mathrm{R}$, Mares $\mathrm{M}$, et al. The effect of bundling medication-assisted treatment for opioid addiction with mHealth: study protocol for a randomized clinical trial. Trials. 2016;17:592.

17. Hochstatter KR, Gustafson DH Sr, Landucci G, et al. A mobile health intervention to improve hepatitis c outcomes among people with opioid use disorder: protocol for a randomized controlled trial. JMIR Res Protoc. 2019;8(8):e12620.

18. COVID-19 (Coronavirus Disease). Wisconsin Department of Health Services; 2020. https://www.dhs.wisconsin.gov/covid -19/index.htm. Accessed 6 May 2020.

19. David RB. Less than $95 \%$ adherence to nonnucleoside reverse-transcriptase inhibitor therapy can lead to viral suppression. Clin Infect Dis. 2006;43(7):939-41. https://doi. org/10.1086/507526.

20. Paterson DL, Swindells S, Mohr J, et al. Adherence to protease inhibitor therapy and outcomes in patients with HIV infection. Ann Intern Med. 2000;133:21-30.

21. StataCorp. Stata statistical software: release 16. College Station: StataCorp LLC; 2019.

22. Parienti J-J, Massari V, Descamps D, Vabret A, Bouvet E, Larouzé $B$, Verdon R. Predictors of virologic failure and resistance in HIV-infected patients treated with nevirapine- or efavirenz-based antiretroviral therapy. Clin Infect Dis. 2004;38(9):1311-6. https ://doi.org/10.1086/383572.

23. Bangsberg DR, Perry S, Charlebois ED, Clark RA, Roberston M, Zolopa AR, Moss A. Non-adherence to highly active antiretroviral therapy predicts progression to AIDS. AIDS. 2001;15(9):1181-3.

24. Hogg RS, Heath K, Bangsberg D, Yip B, Press N, O'Shaughnessy MV, Montaner JSG. Intermittent use of triple-combination therapy is predictive of mortality at baseline and after 1 year of follow-up. AIDS. 2002;16(7):1051-8.

25. Lucas GM, Chaisson RE, Moore RD. Highly active antiretroviral therapy in a large urban clinic: risk factors for virologic failure and adverse drug reactions. Ann Intern Med. 1991;131(2):81-7.

26. Zinski A, Westfall AO, Gardner LI, et al. The contribution of missed clinic visits to disparities in HIV viral load outcomes. Am J Public Health. 2015;105(10):2068-75. https://doi.org/10.2105/ AJPH.2015.302695.

27. Horberg MA, Hurley LB, Silverberg MJ, Klein DB, Quesenberry $\mathrm{CP}$, Mugavero MJ. Missed office visits and risk of mortality among HIV-infected subjects in a large healthcare system in the United States. AIDS Patient Care STDS. 2013;27(8):442-9. https ://doi.org/10.1089/apc.2013.0073.

Publisher's Note Springer Nature remains neutral with regard to jurisdictional claims in published maps and institutional affiliations. 